\title{
The Impact of the Internet on Saudi Arabia Travel Agencies
}

\author{
Fahad Saleh Alolayan ${ }^{1}$ \\ ${ }^{1}$ Department of Tourism and Hotels Management, College Tourism and Archaeology, King Saud University, Saudi \\ Arabia \\ Correspondence: Dr. Fahad Alolayan, Department of Tourism and Hotels Management, College Tourism and \\ Archaeology, King Saud University, Saudi Arabia. \\ Received: December 13, 2017 \\ Accepted: December 30, 2017 \\ Online Published: January 11, 2018 \\ doi:10.5430/ijba.v9n1p81 \\ URL: https://doi.org/10.5430/ijba.v9n1p81
}

\begin{abstract}
This study investigates the impact of the Internet revolution on travel agencies on Saudi Arabia's travel agency market. A reliable and valid three-part questionnaire was developed: the first part collects the basic information on the travel agencies; the second part examines the extent to which travel agencies use the benefits of the Internet for their operations; the last part measures the real impact of the internet on travel agencies with four dimensions. A sample of 50 travel agencies fully participated in this study. The descriptive data of the sample indicates that the travel-agency industry in Saudi Arabia is still very small; more than 50\% of the agencies operate with less than five employees in one or two branches only. More than 55\% of the agencies have less than four years of experience and relatively small capital. In addition, the descriptive data reveals that $72 \%$ of the agencies in the sample do not have their own websites, and only $4 \%$ of the agencies have websites with features that complete customers' transactions without human involvement. The main results assure the importance and the benefit of using the Internet for Saudi Arabia travel agencies; however, they have not yet used most of its advantages. Moreover, they do not see any threat or negative impact to their business from the Internet. A number of recommendations have been provided to this industry, such as using the power of the Internet as a global competition tool, and the opportunity of a major emergence among travel agencies in this market.
\end{abstract}

Keywords: Saudi Arabia, travel agency, internet, impact

\section{Introduction}

Because of the rapid developments in transportation and communications technology, the world has turned into a global village (Levitt, 1983). With the rise of the Internet in the last three decades, almost no little town or thin island has not been influenced by this new technology in one way or another. At the international level, the proportion of Internet use among the people of developed countries amounted to nearly $90 \%$, while in developing countries it has stood at 25\% (www.Internetworldstats.com/stats.htm). And the fact that Saudi Arabia, with an advanced economic status among the world's countries, is at the head of the Gulf countries in terms of Internet use, as there are more than 19 million Internet users (2014 Report, Communications and Information Technology Commission). This number continues to increase because of the continuous decline in the prices of computers and smart phones and the multiplicity of programs and applications, as well as expanding the use of broadband and fiber optics to provide service. Moreover, the adoption of e-government by most of Saudi Arabia's ministries and agencies, which provide their services through the Internet, has led to an increase in the spread of Internet usage. Globally, the role of the Internet in the travel and tourism sector has become essential with outstanding evidences (Standing and Vasudavan, 2001). It seems this sector is one of the few that were able to exploit the benefits of the Internet at early stage. Clearly, the Internet's revolution has changed the landscape of this sector. For instance, many virtual travel agencies have become established as global travel agencies such as www.Booking.com, www.travelcity, and www.tripadvisor.com. Travelers can plan their trips and book flights, hotel rooms, and car rentals, as well as recreational activities, through the websites of these virtual agencies, from their own homes on their own time. Many airlines have abandoned a large segment of their staff in booking and ticket sales offices, and urge customers to complete their reservations and buy tickets online. Commissions paid to travel agencies and tourism for booking and ticket sales have also been reduced. It is clear that the Internet has impacted travel agencies and the tourism sector in different ways, including both numerous opportunities and a number of risks. The existing literature has a stream of academic studies that have examined the impact of the Internet on travel and tourism agencies in different countries 
(Bennett and Buhalis 2003; Poon 2001; Alford 2000). Yet no one academic study has investigated the impact of the Internet on Saudi Arabia travel agencies. The aim of this study is examine:

1- The extent to which Saudi travel agencies' operations have been positively impacted by Internet services;

2- The extent to which Saudi travel agencies have used the Internet as marketing tool;

3- The extent to which the Internet has influenced the market competition; and

4- The extent to which technical barriers have prevented Saudi travel agencies from using all Internet services.

\section{Travel Sector and the Internet}

\subsection{Travel and Tourism Sector in Saudi Arabia}

The travel and tourism in the Kingdom of Saudi Arabia has continued to be a promising business sector due to its status as a religious destination for all Muslims performing Hajj and Umrah. In addition, internal and external tourism has become a fixed component of Saudi Arabia's lifestyle and families spend large portions of their annual budgets on travel. Moreover, expatriates make up nearly 33\% of the Kingdom's population, and they often travel back to their home countries.

This sector has been affected positively and negatively by the resurgence of the Internet, but such challenges and opportunities facing the sector have not been documented through academic research. More than 19 million people traveled outside Saudi Arabia in 2013, while there were 13.4 million incoming travelers in the same year. The number of travel and tourism agencies in the Saudi market and the scope of their deployment, however, do not reflect the size of the travel and tourism industry. The total number travel agencies in this market is only 185, without their branches; $90 \%$ of them with total capital less than half a million dollars and the total number of employees less than six. The average experience of half of these agencies in the travel and tourism sector is five years or less, and their main activities are selling and issuing airlines tickets (www.mas.gov.sa).

\subsection{Internet in Saudi Arabia}

Internet services entered Saudi Arabia early compared to other countries in the Middle East. In 1994, Internet service was connected to a number of educational and research institutions and some other government agencies, and in 1999, Internet services became available to all ministries and government institutions, companies, and individuals. It is around that time more Middle East countries began to use the Internet, and use increased at a rapid rate, rising from 5\% in 2001 to nearly 64\% in 2014. The number of Internet users in Saudi Arabia amounted to about 20 million users, as shown in Figure 1.

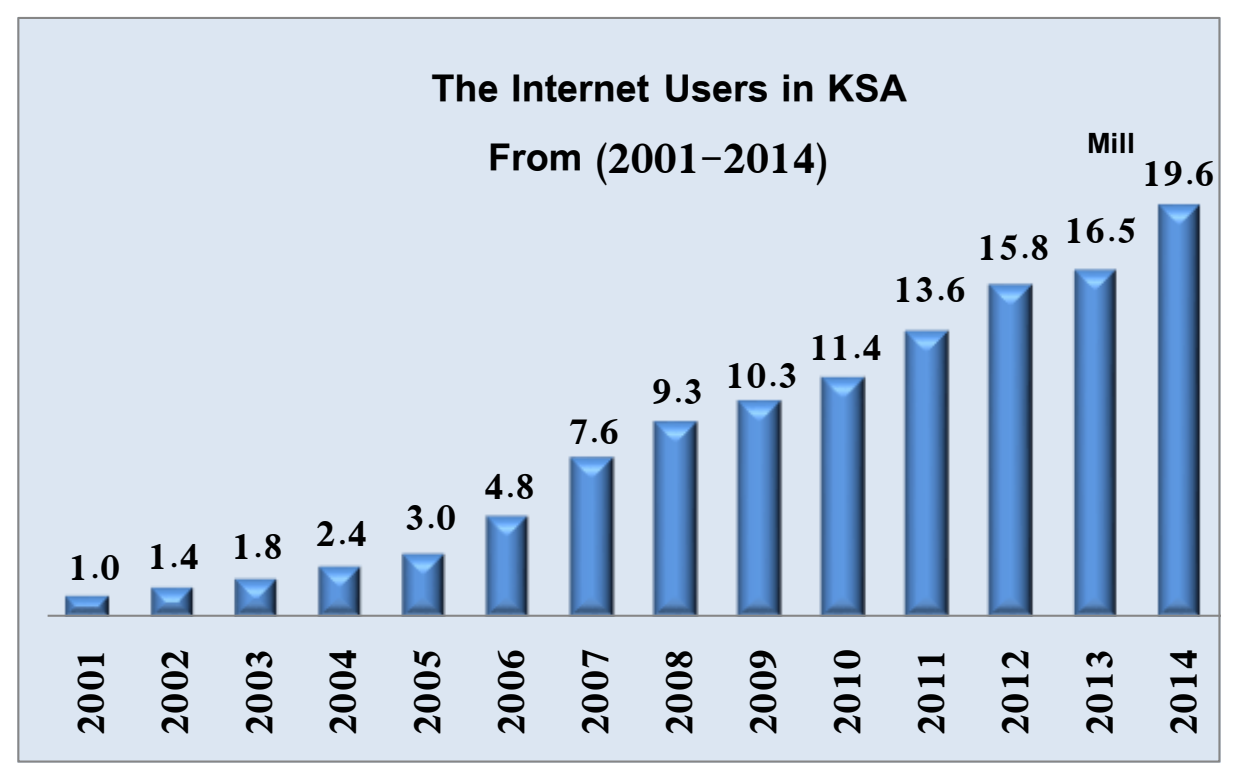

Figure 1. The internet users in KSA from 2001-2014

Source: Communications and Information Technology Commission, KSA 


\section{Literature Review}

Kim (2005) claimed that the successive developments in Internet services provided many valuable opportunities for organizations and medium and small business, allowing to expand their customer base and build strong relationships with relevant parties, such as middlemen and service providers. They determined that travel and tourism agencies, which fall within the medium and small business organizations, benefited from the Internet services since it led to a change in the whole concept of marketing in this sector, especially in developed countries, like the United States and Japan and European countries. Karanasios (2008) stressed that under high global competition, travel and tourism agencies cannot survive without continuity and achieve economies of scale, which help reduce operational costs and gain marketing force, which would not be possible without the optimal use of Internet services. Migiro and Ocholla (2005) explained in their study that Internet applications in the tourism services industry has led to an almost complete change in the purchasing behavior of tourism services. By using the Internet as a marketing channel, working seven days a week and 24 hours a day, tourism customers may choose products and services without the intervention and influence of salesmen. Also it offers the customers the convenience and time savings, as they are able to purchase such services without incurring hardship and time involved in going to a travel agency or tourism office. In addition, the Internet enables customers to compare products and prices of tourism services and choose the most appropriate. Law (2000) in his study stressed the importance of the Internet in the travel agencies and tourism sector, as it is regarded as a means of promotional communication through the availability of information for travelers and tourists 24-7, allowing for quick and easy access and lower costs than standard promotional channels such as advertising and salesmen. Kim (2004) supported the importance of the Internet in the travel and tourism industry by considering it a direct marketing outlet through which the completion of the exchange of products, tourist services, takes place.

In another study, both Bennett and Bushalis (2003) argued that the Internet has become a threat to many traditional travel agencies by allowing travelers and tourists to deal directly with the service provider. For instance, they may complete their reservations directly with airlines and hotels without the need for mediation by travel and tourism agencies. The authors emphasized that service providers are trying to take advantage of Internet services and the disposal of commissions paid to travel agencies and tourism, which on average account for nearly $25 \%$ of operating costs. The CEO of British Airways has said that the cost of commissions and travel agencies are the third-highest operational costs, after the costs of human resources and fuel. In the same vein, Schwartz and Zea (1999) indicated that American West Airline Company was able to reduce direct costs by selling through the Internet, where the cost of ticket issuance was reduced from $\$ 23$ to 6 . The authors mentioned that the company is trying to shift the bulk of its sales from travel agencies, which are equivalent to $75 \%$ of total sales, to direct sales through airline websites $\backslash$ to reduce the cost of sales and achieve a high degree of operational efficiency.

As for the hotel industry, Bennett and Lai (2005) said the Internet has provided hotels with an economic opportunity, as it enables the hotels to deal directly with hotel guests rather than travel agencies, thereby reducing costs. The customer is now able to make a reservation for a room and accompanying services and payment through the hotel's website. But both Sangster (2001) and O 'Connor (2001) discuss the hotel sector's ability to abandon traditional travel agencies to reduce the cost of sales; they believe that the hotel sector can achieve many benefits in the marketing field in spite of commissions paid to travel and tourism agencies. The Internet empower hotels to obtain the necessary data for market research at a low cost and high speed, such as data that measures the level of customer satisfaction and loyalty, which helps hotels improve the provision of their services. It also helps by allowing hotels to add video clips that provide the prospective client virtual tours of hotel facilities, which helps the customer build amental picture of the hotel and reduces the gap between the expected quality and quality provided.

On the other hand, Blank (1999) claimed hotel clients prefer to deal with travel and tourism agencies when it comes to hotel reservations, instead of using the Internet directly because of safety issues related to the use of credit cards. He mentioned hotel clients hotels would visit the hotel website to find information about hotel facilities, location, and other information to make a decision, and then turn to traditional travel agencies to book a room. Moreover, a number of researchers have noted the Internet's ability to marginalize the role of traditional travel agencies. Tyler (2000) and Williams (1999) said that traditional travel and tourism agencies need to restore their marketing activities and functions and take advantage of online services to achieve economies of scale without high new investments. The researchers also confirmed that the world of the Internet has created an opportunity for local and global virtual travel agencies such as Booking.com, Expedia.com, Travel.com, and Priceline.com, which have become able to compete in travel tourism by providing real value for both parties, the service providers and the clients. 
Prebezac and Josip (2004) investigated the impact of the Internet on Croatia's travel agencies. They found that travel agencies have recognized the importance of the Internet in their field and utilized the major benefits of the Internet in their operations and marketing activities, such as promoting tourism products and services, improving the mental image of the agency, providing a vast amount of data information to current and potential clients and business, and allowing customers to complete their reservations through the agency's website.

In a different direction from previous studies, Wynne et al. (2001) claimed that the Internet has become a real threat to traditional travel agencies, especially in developed countries, for a number of reasons, on top of which is the high level of Internet use among the peoples of those countries, as they compare prices and calculate the cost of time and effort in order to get tourist products for less through Internet. So the researchers concluded that their study confirms that the Internet will eliminate the traditional role of travel agencies if these agencies do not adopt a virtual agency approach to a high degree.

\section{The Study Methodology}

This study sought to determine the impact of the Internet on the travel agencies and the tourism sector in the Kingdom of Saudi Arabia by answering the four research questions. Exploratory approach has been used to carry out this study, and a three-part questionnaire was developed. The first part includes the basic and general information on the travel agencies. The second part is concerned with identifying the extent to which travel agencies use Internet services, which includes nine items. These items were measured by nominal scales of only two levels (yes or no), because the purpose of this section is to identify whether a travel agency has such Internet applications or not. The last part of the questionnaire was designed to measure the impact of the Internet on travel agencies with a Likert Scale with five degrees. It included four key dimensions: the first dimension contains seven items to measure the impact on operational costs; the second dimension is concerned with the measurement of the extent the Internet is used as a marketing tool and includes seven items; the third dimension includes six items to measure the Internet's impact on the level of competition; and finally, the fourth dimension with six items measures the technical barriers that prevent Saudi travel agencies from using all Internet services.

The research population includes all travel agencies that are licensed by the Saudi Commission for Tourism and National Heritage and listed on its website www.mas.gov.sa. There are a total of 167 agencies, without including branches and after excluding agencies specializing in Hajj and Umrah. The sample size is 45 agencies, which is about $27 \%$ of the total research population. The sample was drawn via a random sampling method according to the regions of the Kingdom Saudi Arabia, as shown in Table 1. With regard to statistical analysis methods, descriptive statistics, such as percentages and frequencies, the arithmetic average to identify the extent of adopting Internet services, and a T-test were used to measure the four dimensions of the study.

Table 1 . The study sample

\begin{tabular}{lcclcc}
\hline Region & $\begin{array}{c}\text { Number } \\
\text { of Agencies in } \\
\text { Each Region }\end{array}$ & $\begin{array}{c}\text { Number of } \\
\text { Agencies on the } \\
\text { Sample }\end{array}$ & Region & $\begin{array}{c}\text { Number of } \\
\text { Agencies in } \\
\text { Each Region }\end{array}$ & $\begin{array}{c}\text { Number } \\
\text { of Agencies on the } \\
\text { Sample }\end{array}$ \\
\hline Riyadh & 67 & 14 & Asir & 3 & 1 \\
Makah & 62 & 13 & Jouf & 3 & 1 \\
East Region & 26 & 7 & Najran & 2 & 1 \\
Qussam & 6 & 2 & Jizan & 1 & 1 \\
Madinh & 5 & 2 & Albahah & 1 & 1 \\
Hail & 3 & 1 & Tabuk & 1 & 6 \\
Total (45) & & 39 & & & 1 \\
\hline
\end{tabular}

\section{Statistical Analysis}

From the sample description in Table 2, there are three important issues that need to be highlighted: number of branches, years of experience, and number of employees. With regard to the number of branches, only $4.5 \%$ of the sample agencies have ten branches, and $13.5 \%$ of them have more than five but less than ten branches, while a majority of these agencies (53\%) have between two and four branches. The remaining agencies (29\%) operate with one branch only. When it comes to the years of experience, the data shows that only $7 \%$ of the agencies have more than ten years of experience, and $20 \%$ of the sample have between five and ten years of experience, while the majority (60\%) of the study sample has between three and four years of experience; the remaining $13 \%$ of the sample 
has between one and two years of experience in this sector. The number of employees, as mentioned previously, in most the agencies are very small: $51 \%$ of the sample employ less than ten employees, $36 \%$ employ more than ten yet less than fifty employees, and $11 \%$ have more than fifty but less than a hundred employees; there is only one agency in the sample that employs more than one hundred employees.

Table 2. The sample description

\begin{tabular}{|c|c|c|c|c|c|}
\hline Number of Branches & 10 or More & From 5 to 9 & From 2 to 4 & Only 1 & Total \\
\hline $\begin{array}{l}\text { Numbers of agencies } \\
\text { Percentage }\end{array}$ & $\begin{array}{c}2 \\
(4.5 \%) \\
\end{array}$ & $\begin{array}{c}6 \\
(13.5 \%) \\
\end{array}$ & $\begin{array}{c}24 \\
(53 \%) \\
\end{array}$ & $\begin{array}{c}13 \\
(29 \%) \\
\end{array}$ & $\begin{array}{c}45 \\
(100 \%) \\
\end{array}$ \\
\hline Years of experience & 10 or More & From 5 to 9 & From 2 to 4 & Only 1 & Total \\
\hline $\begin{array}{l}\text { Numbers of agencies } \\
\text { Percentage }\end{array}$ & $\begin{array}{c}3 \\
(7 \%) \\
\end{array}$ & $\begin{array}{c}9 \\
(20 \%) \\
\end{array}$ & $\begin{array}{c}27 \\
(60 \%) \\
\end{array}$ & $\begin{array}{c}6 \\
(13 \%) \\
\end{array}$ & $\begin{array}{c}45 \\
(100 \%) \\
\end{array}$ \\
\hline Number of Employees & From 100 or More & From 50 to 99 & From 10 to 49 & Less than 10 & Total \\
\hline $\begin{array}{l}\text { Numbers of agencies } \\
\text { Percentage }\end{array}$ & $\begin{array}{c}1 \\
(2 \%)\end{array}$ & $\begin{array}{c}5 \\
(11 \%)\end{array}$ & $\begin{array}{c}16 \\
(36 \%) \\
\end{array}$ & $\begin{array}{c}23 \\
(51 \%) \\
\end{array}$ & $\begin{array}{c}45 \\
(100 \%) \\
\end{array}$ \\
\hline
\end{tabular}

Table 3 shows that the business activities that Saudi Arabia travel agencies deal with range from one business activity to seven. It is clear that ticket sales are the core business for these agencies while other types of business activities are limited. As shown in the Table, only $11 \%$ of the sample deals with recreation programs, and only $22 \%$ of the sample can book hotel rooms.

Table 3. Travel agencies business activities

\begin{tabular}{lcccc}
\hline \multicolumn{1}{c}{ Business Activities } & \multicolumn{2}{c}{ Available Activities } & No \\
& Yes & & & $\%$ \\
\hline Ticket's Sell & 45 & $100 \%$ & 0.0 & 0.0 \\
Issuing International Drive License & 30 & $67 \%$ & 15 & $33 \%$ \\
Hotel Reservation & 10 & $22 \%$ & 35 & $78 \%$ \\
Rental Car's Reservation & 10 & $22 \%$ & 35 & $78 \%$ \\
Villa \& Apartment Reservation & 8 & $18 \%$ & 37 & $82 \%$ \\
Recreation Programs & 5 & $11 \%$ & 40 & $89 \%$ \\
Education Services & 24 & $53 \%$ & 10 & $47 \%$ \\
\hline
\end{tabular}

Table 4 indicates the usage of Internet service among travel agencies. Only $29 \%$ of the sample have websites, but all remaining agencies responded that they are considering the establishment of a website in the near future. In terms of the existence of protocol SSL (Secure Sockets Layer), which ensures security of circulated information over the Internet, no single agency has it in its website. On the other hand, $60 \%$ of the sample communicate with their customers via e-mail in one way or another. In terms of completing customer reservations online, only two agencies enable their customers to do so, yet without enabling them to process their purchase of tourism services via the Internet. Finally, the above Table shows that all travel agencies in the sample are mainly dependent on the Internet in both internal operational processes as well as external operational processes with service providers such as airlines, hotels, and others. 
Table 4. Internet services utilized by travel agencies

\begin{tabular}{lcccc}
\hline \multicolumn{1}{c}{ Internet Services } & \multicolumn{3}{c}{ Availability of Services } \\
& \multicolumn{2}{c}{ Yes } & \multicolumn{2}{c}{ No } \\
& $\#$ & $\%$ & $\#$ & $\%$ \\
\hline Having website & 13 & $29 \%$ & 32 & $71 \%$ \\
Intention to have Website Soon & 32 & $71 \%$ & 13 & $29 \%$ \\
Communicating with customers Via Email & 27 & $60 \%$ & 18 & $49 \%$ \\
Completing Reservations Via Website & 2 & $4 \%$ & 43 & $96 \%$ \\
Completing sell Via website & 0.0 & $0.0 \%$ & 45 & $100 \%$ \\
Updating website frequently & 13 & $29 \%$ & 32 & $771 \%$ \\
Having SSL Protocol & 0.0 & $0.0 \%$ & 45 & $100 \%$ \\
Dealing with service providers Via Internet & 45 & $1000 \%$ & 0.0 & $0.0 \%$ \\
\hline
\end{tabular}

The results of the four research questions, which are concerned with exploring the extent of using the Internet service, are presented in Table 5. On a five-point Likert scale, the Internet's influence on operational costs dimension is statistically significant $(\mathrm{P}<.05)$ and had the highest mean score $(\mathrm{M}=3.75, \mathrm{SD}=0.343)$, followed by Internet as a marketing tool dimension, which is also statistically significant $(\mathrm{P}<.05)$ with a mean score $(\mathrm{M}=3.72, \mathrm{SD}=0.378)$. The influence of the Internet on the market completion dimension is not statistically significant $(\mathrm{P}>.05)$ and has a mean score $(\mathrm{M}=2.32, \mathrm{SD}=0.347)$, and lastly the dimension of barriers to utilize Internet services is also not statistically significant $(\mathrm{P}>.05)$ with mean score $(\mathrm{M}=2.66, \mathrm{SD}=0.364)$.

Table 5. Statistical tests for the four dimensions

\begin{tabular}{lcccc}
\hline Dimensions & Means & Std. Deviation & \multicolumn{2}{c}{ Level of significance } \\
\cline { 3 - 5 } & & & T-test & P-Value \\
\hline Internet's influence on operational efficiency & $(3.75)$ & $(0.343)$ & $(10.63)$ & $(0.0000)$ \\
Internet as marketing tool & $(3.72)$ & $(0.378)$ & $(13.14)$ & $(0.0000)$ \\
Internet's influence on market competition & $(2.32)$ & $(0.347)$ & $(06.52)$ & $(0.0631)$ \\
Barriers to utilize Internet services & $(2.66)$ & $(0.364)$ & $(07.37)$ & $(0.0540)$ \\
\hline
\end{tabular}

\section{Results and Recommendations}

Statistical results indicate that the Saudi travel agency sector is still emerging, as most agencies in this sector are small with a few or single branch and with a limited number of employees; their core business is selling tickets to workers and families with a few exceptions. With regard to the utilization of the Internet services, results showed that the vast majority of the sample do not have websites despite their awareness of the importance of Internet services in the travel sector. Yet they claimed that they are in the process of the developing websites in the near future. It turns out that the main communication mode with their customers is the traditional one, with the exception of a few agencies that use e-mail to communicate with their customers and suppliers. The sample description showed that there are a few agencies that have websites and allow their customers to complete bookings through the Internet but do not enable them to complete the payment process.

At the level of the Internet influence over travel agencies' operations, the results showed that the Internet highly affected their major operations, especially by utilizing their networks with their main suppliers such as airlines and hotels. Moreover, the email system enables them to quickly communicate informally, internally and externally. The results indicated that the Internet is a very effective marketing tool in teams of self-promotion and communication channels, yet it has not worked as a 24 hour, seven days a week distribution channel in this sector as well as it is in the global travel industry. They were not able to use it as a distribution channel mainly because their target segments, at the present time, are not involved with high tech. In terms of the actual impact in the market competition, there was no increase or decrease in the agencies sales yet, while the situation in most countries is very different. The competition between traditional travel agencies and virtual ones is too high; moreover, most global airlines and hotels have their own websites and urge their customers to deal with them directly through their sites.

On the other hand, the Internet has had a positive impact on the number of tourist services provided by travel agencies because of the ease of communication between tourism service providers and travel agencies. They have 
become able to speedily deliver services around the clock. However, it has not had a significant impact in reducing promotional costs and costs of human resources. Finally, the results showed limited agencies are using the Internet to complete customers' purchases.

In light of the current results and as compared with the results of previous studies in a number of countries, it is clear that this sector has to adopt a number of strategies. First, to face global competition from virtual travel agencies, Saudi Arabia travel agencies have to emerge with each other. Second, these travel agencies have to capitalize on the advantages of the Internet through the creation of websites with full services. Third, those agencies should retain some their current methods of providing tourism services since most of the target segments are not Internet-oriented currently.

\section{References}

Alford, P. (2000). E-Business in the Travel Industry. Travel \& Tourism Intelligence, London, 39-53.

Bennett, M., \& Buhalis, D. (2003, January). Tourism and Travel Distribution: The Travel Agent's Perspective. Insight D, 25-30, English Tourism Council.

Bennett, M., \& Lai C. (2005). The Impact of the Internet on Travel Agencies in Taiwan. Journal of Tourism and Hospitality Research, 6(1), 1-17.

Blank, D. (1999, September). Raising the Internet Stakes. Airline Business, 90-92.

Karanasics, S. (2008). An E-commerce Framework for Small Tourism Enterprises in Developing Countries. Doctorate thesis, School of Information Systems, Faculty of Business and Law, Victoria University.

Kim, C. (2004). E-tourism: an Innovative Approach for the Small and Medium-sized Tourism enterprises (SMTEs) in Korea. Retrieved 16 February 2009, from http://www.oecd.org/dataoecd/56/13/34268048.pdf

Kim, C. (2005). Enhancing the Role of Tourism SMEs in Global Value Chain: a Case Analysis on for Travel Agencies and Tour Operators in Korea. Global Tourism Growth: a Challenge for SMEs. Retrieved 20 July 2008, from http://www.oecd.org/dataoecd/56/13/34268048.pdf

Law, R. (2000). Internet in Travel and Tourism-Part 1. Journal of Travel and Tourism Marketing, 9(3), 65-71. https://doi.org/10.1300/J073v09n03_05

Levitt, Theodore. (1983, May-June). The Globalization of Markets. Harvard Business Review, 61, 2-11.

Migiro, S, \& Ocholla, D. (2005). Information and Communication Technologies in Small and Medium Scale Tourism Enterprises in Durban, South Africa. Information Development, 21(4), 283-294. https://doi.org/10.1177/0266666905060089

O'Connor, P. (2001). The Changing Face of Hotel Electronic Distribution. Travel \& Tourism Analyst, 5, 61-80.

Poon, A. (2001). The Future of Travel Agents. Travel \& Tourism Analyst, 3, 57-80.

Prebezac, D, \& Josip. (2004, June). The Use of Internet: An Opportunity or a Threat to Traditional Distribution in Tourism (2nd ed.). International Conference: An Enterprise Odyssey Building Competitive Advantage. Zagreb 17-19.

Sangster, A. (2001). The Importance of Technology in the Hotel Industry. Travel \& Tourism Analyst, 3, 43-56.

Schwartz, N., \& Zea, M. (1999, July). Surfing for value. Airline Business, 68-70.

Tyler, C. (2000). Ticketing and Distribution in the Airline Industry. Travel \& Tourism Analyst, 2, 83-105.

Williams, A. P., \& Palmer, A. J. (1999). Tourism Destination Brands and Electronic Commerce: Towards Synergy?. Journal of Vacation Marketing, 5(3), 263-275. https://doi.org/10.1177/135676679900500306

Wynne, C., Pierre, B., Leyland, P., Michael, E., \& Jlie, N. (2001). The Impact of the Internet on the Distribution Value Chain: The Case of the South African Tourism Industry. International Marketing Review, 18(4), 2001. https://doi.org/10.1108/EUM0000000005934 